\section{THU0297 A NOVEL ULTRASOUND SCORING SYSTEM FOR GIANT CELL ARTERITIS}

S. Monti ${ }^{1,2}$, C. Ponte ${ }^{3}$, G. Carrara ${ }^{4}$, F. Rumi ${ }^{4}$, A. Hutchings ${ }^{5}$, B. Dasgupta ${ }^{6}$, R. Luqmani ${ }^{1} .{ }^{1}$ NDORMS, Rheumatology Department, University of Oxford, Oxford, United Kingdom; ${ }^{2}$ Rheumatology, University of Pavia, IRCCS Policlinico San Matteo Foundation, Pavia, Italy, Pavia, Italy; ${ }^{3}$ Rheumatology, Hospital de Santa Maria, CHLN, Lisbon, Portugal; ${ }^{4}$ Epidemiology Unit, Italian Society of Rheumatology, Milan, Italy; ${ }^{5}$ Department of Health Services Research and Policy, London School of Hygiene and Tropical Medicine, London; ${ }^{6}$ Rheumatology, Southend University Hospital, NHS Foundation Trust, Westcliff-on-Sea, United Kingdom

Background: Colour duplex sonography (CDS) can be used for giant cell arteritis (GCA) to detect inflammatory oedema of the vascular wall, known as "halo". A standardized, quantitative score to grade the severity and extension of vascular involvement detected by CDS has not yet been developed.

Objectives: To develop and test different scoring models of CDS findings in patients with new onset GCA, and to correlate the models with final diagnosis, histologic findings, and outcome.

Methods: We selected patients with a positive CDS and a confirmed diagnosis of GCA from the Temporal Artery Biopsy vs Ultrasound in Diagnosis of GCA (TABUL) study (1). We designed CDS models combining different ultrasonographic information based on available evidence, or hypothesized clinical relevance of size, anatomical distribution, and extent of halos, summing up to a final numeric score.

Results: We included 135 GCA patients (male/female: 43/92), age $73.3 \pm 8$. Fourty four patients $(24 \%)$ had a positive CDS, but not a final diagnosis of GCA. We designed 8 different CDS models (Figure 1). Models 1, 4, 6, and 7 were significantly associated with a confirmed diagnosis of GCA (Table 2). Model 7 better discriminated patients with GCA from non-GCA: area under the curve (AUC): $0.844(0.766-0.923)$. All, except models 5 and 8 , correlated with a temporal artery biopsy (TAB) result diagnostic for GCA. Most models correlated with histologic findings involving the media or transmural infiltrate, but not with small vessel or adventitial involvement. None of the models correlated with permanent ischaemic sequelae, however, the low number of events might have affected the results.

\begin{tabular}{|c|c|}
\hline \multicolumn{2}{|c|}{ Figure 1. Ultrasound scoring models } \\
\hline Model & Scoring formula \\
\hline Model 1 & Sum of sites with halos in TA and $\mathrm{AX}$ \\
\hline Model 2 & Defined as either bilateral halo on any TA branches $\mathrm{OR}$ bilateral halo on $\mathrm{AX}$ \\
\hline Model 3 & $\begin{array}{l}\text { (Number of sites with halo on TA * average halo thickness among TA } \\
\text { branches) + (number of sites with halo on } \mathrm{AX}^{*} \text { average halo thickness or } \\
\mathrm{AX} \text { ) }\end{array}$ \\
\hline Model 4 & $\begin{array}{l}\text { (Number of sites with halo on } \mathrm{TA}^{*} \text { maximum halo thickness among TA } \\
\text { branches) }+ \text { (number of sites with halo on } \mathrm{AX}^{*} \text { maximum halo thicknes } \\
\text { among } \mathrm{AX} \text { ) }\end{array}$ \\
\hline Model 5 & $\begin{array}{l}\text { (Average halo thickness among TA }+ \text { add " } 1 \text { " if bilateral halo on TA) + } \\
\text { (average halo thickness among TA + add " } 1 \text { " if bilateral halo on AX) }\end{array}$ \\
\hline Model 6 & $\begin{array}{l}\text { (Maximum halo thickness among TA }+ \text { add "1" if bilateral halo on TA) } \\
\text { (maximum halo thickness among AX }+ \text { add "1" if bilateral halo on AX) }\end{array}$ \\
\hline Model 7 & $\begin{array}{l}\text { (Maximum thickness among TA * } 2 \text { if bilateral })+(\text { maximum halo thicknes } \\
\text { among } \mathrm{AX}^{*} 2 \text { if bilateral) }\end{array}$ \\
\hline Model 8 & $\begin{array}{l}\text { (Average thickness among } \mathrm{TA} * 2 \text { if bilateral) }+ \text { (average halo thicknes } \\
\text { among } \mathrm{AX}^{*} 2 \text { if bilateral) }\end{array}$ \\
\hline
\end{tabular}

Conclusions: The CDS findings that better correlate with a diagnosis of GCA, and TAB findings are: the number of positive sites, the size of the halo (maximum, rather than average thickness), and the presence of bilateral halos, variably combined into a unique score. We plan to test these models in a new cohort of patients with suspected GCA, to determine their validity.

References:

[1] Luqmani R, Lee E, Singh S, et al. The Role of Ultrasound Compared to Biopsy of Temporal Arteries in the Diagnosis and Treatment of Giant Cell Arteritis (TABUL): a diagnostic accuracy and cost-effectiveness study.Health Technol Assess 2016;20:1-238.

Disclosure of Interest: None declared

DOI: 10.1136/annrheumdis-2017-eular.4069

\section{THU0298 LONG TERM OUTCOME OF PATIENTS WITH TAKAYASU ARTERITIS- A SINGLE CENTRE STUDY}

R. Goel ${ }^{1}$, D. Danda ${ }^{1}$, G. Joseph ${ }^{2}$, A. Nair ${ }^{1}$, V. Jayseelan ${ }^{3}$, L. Jayaseelan ${ }^{3}$, S. Kumar ${ }^{4}$, P. Bacon ${ }^{5} .{ }^{1}$ Clinical Immunology and Rheumatology; ${ }^{2}$ Cardiology; ${ }^{3}$ Biostatistics; ${ }^{4}$ Child Health, Christian Medical College, Vellore, Tamil Nadu, Vellore, India; ${ }^{5}$ School of Immunity and Infection, University of Birmigham, Birmigham, United Kingdom

Background: Takayasu Arteritis (TA), a large vessel vasculitis is characterised by a variable clinical course and outcome that differs across populations. Most studies are limited by small sample size.

Objectives: (i) To study treatment outcome in our TA patients with a follow up of $\geq 12$ months (ii) Construct a prediction model for subset of patients with sustained inactive disease.

Methods: Consecutive patients with TA attending our clinics between 1998 and April 2016 were recruited. Details of baseline demography, clinical profile, angiography, disease extent using DEI.Tak, laboratory parameters and TADS (Takayasu arteritis damage score) were recorded. At each follow up visit, disease activity was assessed by Indian Takayasu Activity score (ITAS-2010 (CRP) and imaging, while damage was assessed by TADS for patients who followed up for $\geq 12$ months (retrospectively for 179 and prospectively for 72 patients). Treatment response was classified as complete response (CR), partial response and no-response. Sustained inactive disease was defined as maintenance of CR throughout the follow up with steroid dose reduced to $\leq 5 \mathrm{mg} /$ day. Relapse was defined as return of active disease after CR. Statistical analysis was performed using SPSS-16. Intergroup comparisons were performed by nonparametric test. Logistic regression was used for determining independent associations. Optimal cut off values were determined using receiver operating curve and prediction model was constructed. Efficacy of medications was compared by Cox proportional hazards model.

Results: Baseline details were noted for 503 patients: mean age at onset of $25.6 \pm 11.1$ years, disease duration $12(6-48)$ months, diagnostic delay 6 (3-24) months) and $77.9 \%$ were females.

Among 251 patients with follow up of at least 12 months, $95.2 \%$ received steroids along with II line immunosuppressant in 93.6\% (mycophenolate in $63.7 \%$ ). Tocilizumab was given induction or rescue therapy to 44 patients. Revascularisation procedures were performed in $71.7 \%$. Complete (ITAS $2010=$ $0, \mathrm{CRP}<6 \mathrm{mg} / \mathrm{L}$, angiowise non-progression) and partial response was achieved in 176 patients $(70.1 \%)$ and $42(16.7 \%)$ respectively within 6 months.

During a median follow up of 42 (IQR: 24-81) months, 116 (46.2\%) maintained complete response till their last follow up with cumulative relapse free survival of $83 \%, 70 \%$ and $55 \%$ at 1,2 and 3 years respectively. A model including baseline $\mathrm{CRP} \leq 6.1 \mathrm{mg} / \mathrm{L}$, type 4 disease and DEI.Tak $<9$ predicted sustained inactive disease with an AUC of $70.2(63.3-77.2, p=0.000)$. Initial steroid dosage of $0.5 \mathrm{mg} / \mathrm{kgday}$ was similar to $1 \mathrm{mg} / \mathrm{kg} /$ day in terms of response or relapse. Overall, there were only $15(5.9 \%)$ patients who never responded to treatment. There were 2 fatalities. At the last visit, $176(70.5 \%)$ had stable disease. Damage progression (delta TADS) was lower in patients with sustained inactive disease than the rest, $\mathrm{p}=0.000$.

Conclusions: Medical management arrested disease activity, damage progression and mortality in our cohort. Low baseline CRP and DEI.Tak scores and type 4 disease independently predicted sustained inactive disease.

Disclosure of Interest: None declared

DOI: 10.1136/annrheumdis-2017-eular.4258

\section{THU0299 UNDERSTANDING THE HETEROGENEITY OF LARGE-VESSEL VASCULITIDES}

E. Tombetti ${ }^{1}$, A. Ambrosi ${ }^{2}$, C. Godi ${ }^{2}$, B. Ariff ${ }^{1}$, A.A. Manfredi ${ }^{2}$, J. Mason ${ }^{1}$ ${ }^{1}$ Imperial College London and Imperial College NHS Trust, London, United Kingdom; ${ }^{2}$ San Raffaele Hospital and Vita-Salute University, Milan, Italy

Background: Adult large-vessel vasculitides (LVV) are rare conditions, currently classified as two different diseases, Takayasu arteritis (TA) and giant cell arteritis (GCA), on an empirical basis. Insight into phenotypic and pathogenic differences between the two is scarce at best. Arterial involvement, despite being the central disease feature, has been poorly addressed by research. We have developed two novel, imaging-based scores (the arteritis stenosis score [ASS] and arteritis dilation score [ADS]). ASS and ADS define stenotic and aneurysmal disease in a

Abstract THU0297 - Table 2. Correlation of the different models with clinical and histologic variables

\begin{tabular}{|c|c|c|c|c|c|c|c|c|c|c|}
\hline \multirow[t]{2}{*}{ Median (IQR) } & & \multirow[t]{2}{*}{ Model 1} & \multicolumn{2}{|c|}{ Model 2} & \multirow[t]{2}{*}{ Model 3} & \multirow[t]{2}{*}{ Model 4} & \multirow[t]{2}{*}{ Model 5} & \multirow[t]{2}{*}{ Model 6} & \multirow[t]{2}{*}{ Model 7} & \multirow[t]{2}{*}{ Model 8} \\
\hline & & & 0 & 1 & & & & & & \\
\hline \multirow[t]{3}{*}{ Predicting a diagnosis of GCA } & 0 & $2(1-3)$ & $25(57 \%)$ & 19 (43\%) & $3(2-4.2)$ & $1(0.4-2.3)$ & $2.7(1.9-3.4)$ & $1(0.4-1.8)$ & $0(0-1.4)$ & $1.3(0.6-2.7)$ \\
\hline & 1 & $3(1-5)$ & $60(44 \%)$ & 75 (56\%) & $3.3(1.8-6.2)$ & $2.1(0.8-4.4)$ & $3.2(2.1-3.7)$ & $1.6(0.7-2.3)$ & $2(1.2-2.8)$ & $1(0-1.8)$ \\
\hline & $\mathrm{p}$ & 0.028 & \multicolumn{2}{|c|}{0.21} & 0.52 & $<0.001$ & 0.47 & 0.003 & $<0.001$ & 0.35 \\
\hline \multirow[t]{3}{*}{ TAB diagnostic for GCA } & 0 & $2(1-3.5)$ & $31(61 \%)$ & 20 (39\%) & $2.5(1.2-3.4)$ & $1(0.6-2.4)$ & $2.1(1.2-3.5)$ & $1.2(0.4-1.7)$ & $1.4(1-2)$ & $0.3(0-2.2)$ \\
\hline & 1 & $3(2-5)$ & $24(32 \%)$ & $52(68 \%)$ & $5(2.9-7.5)$ & $2.8(1.8-6)$ & $3.5(2.7-4)$ & $1.9(1.4-2.5)$ & $2.2(1.4-3)$ & $1.1(0.2-1.6)$ \\
\hline & $\mathrm{p}$ & $<0.001$ & \multicolumn{2}{|c|}{0.002} & 0.007 & $<0.001$ & 0.064 & $<0.001$ & 0.008 & 0.90 \\
\hline \multirow[t]{3}{*}{ Transmural infiltrate } & 0 & $2(1-3.3)$ & $34(61 \%)$ & 22 (39\%) & $2(1.3-3.4)$ & $1.1(0.6-2.4)$ & $1.9(1.1-3.3)$ & $1.1(0.4-1.7)$ & $1.4(1.1-2)$ & $0.2(0-2.2)$ \\
\hline & 1 & $3(2-4)$ & $6(23 \%)$ & 20 (77\%) & $2.8(1.6-3.2)$ & $2.6(1.5-3.6)$ & $2.8(2.2-3.1)$ & $1.9(1.5-2.3)$ & $1.7(1.2-2.5)$ & $0.8(0.2-1.2)$ \\
\hline & $\mathrm{p}$ & 0.011 & \multicolumn{2}{|c|}{0.003} & 0.96 & 0.003 & 0.51 & 0.002 & 0.29 & 0.96 \\
\hline
\end{tabular}

